\title{
REVIEW \\ Lessons Learned, Promises Kept: A Biologist's Eye View of the Genome Project
}

\author{
Shirley M. Tilghman ${ }^{1}$ \\ Department of Molecular Biology, Howard Hughes Medical Institute, Princeton University, \\ Princeton, New Jersey 08544
}

The United States Human Genome Project celebrated its fifth official birthday this year. This seemed like a suitable time to ask whether there has been an impact of the Project on the hearts, minds, and most important, experiments of practicing biologists. Before considering this question, it occurred to me that it would be instructive to go back to 1988 , before the project began, and remember how the biology community first viewed it. At that time there were three major criticisms. The first was that the sequence of the human genome would be uninterpretable; it would sit in a huge white elephant of a data base that would lie dormant because we wouldn't know how to read the information in it. The second criticism was that it was going to be really BORING science: It would be boring to do it and the outcome would be boring. Who would be willing to do it? Given the large number of people now happily engaged in genomic research, this criticism seems, in retrospect, shortsighted. Short of people we're not. The final criticism, and probably the most serious concern, was that the project would take scarce resources away from "interesting" science-in other words, "my science."

I think it's safe to say that one hears very little discussion of this kind any more. What I hear more often is exemplified by a thoughtful commentary written by R.R. West and Richard McIntosh in December's issue of the Journal of Cell Biology: "Future biologists will be working in an environment defined by a wondrous wealth of information about genome structure. It is mindboggling to think of the ways in which our experimental lives will be changed as a result. No field of biology will be untouched" (McIntosh

This is an adaptation of the keynote speech given at the Cold Spring Harbor Laboratory Genome Mapping and Sequence meeting, May 1996.

'E-MAIL' stilghman@molbiol.princeton.edu; FAX (609) 2583345. and West 1995). Now, Dick McIntosh is a cell biologist's cell biologist-someone whose work could not be further away from genomics. And yet, this is Dick McIntosh's view of the genome in 1996.

I happen to agree with him. There has indeed been a sea-change in the opinion of the scientific community over the last six to eight years. I offer two reasons for this: The first is taken from that old chestnut that "a conservative is a liberal who has just been mugged." Here's my version: "A genome enthusiast is a genome critic who just got a hit in the EST [expressed sequence tag] data base." This is called the "theory of enlightened self-interest." There is nothing that turns someone into an enthusiast faster than not having to sequence their gene after all. But there's a deeper reason, and I call this "the model organism as ace in the hole." When the Human Genome Project was originally being conceived, it was not obvious that it should include model organisms. The decision to do so was one of the most perceptive decisions that was made by the original National Research Council Committee that put together the blueprint for the U.S. version of the Human Genome Project.

First of all, it ensured that the project belonged to biology, not to human geneticists. It was an inclusive decision, a decision that brought in rather than kept out. It also attracted excellent scientists to genomics-people who would never have joined the project had it been restricted to human genetics. Some of these individuals have transformed the field of genomics. It also avoided what I call the "SSC political problem." There are many physicists who believe that one of the reasons why the superconducting supercollider project failed was that there was going to be no payoff until someone put in the key and pushed the button. That event was years down the line, after many millions of dollars had been spent. The decision to fund model organism genome 


\section{TILGHMAN}

projects meant that the problem of delayed gratification was avoided. For example, we have just celebrated a major milestone in the Human Genome Project with the publication of the sequence of the yeast genome. Since the beginning of the project, benefits have accrued on a regular basis.

How, then, has the basic biological community benefited? In considering this I am going to ignore human biology, where the benefits are perhaps more obvious, and restrict my comments to model organism biology.

\section{Lessons Learned from the Human Genome Project. Lesson 1: Information is Power}

The first lesson learned from the Human Genome Project is that information is power. In other scientific communities, such as physics or engineering, the one criticism of the Human Genome Project that they could never understand was the first one I noted above-that the sequence would be uninterpretable. In those communities the idea of information as anything but good is simply inconceivable.

The systematic acquisition of information, even before knowing precisely how it will be useful in the future, is hardly a new idea in biology. A beautiful example from the pregenome era comes from the work of Victoria Foe, a developmental biologist, who set out to map the mitotic domains in the Drosophila embryo. During the first 13 cell divisions of Drosophila embryogenesis, the nuclei, which are in a syncytial blastoderm, divide synchronously. At the end of the 13th division cycle, asynchrony sets in. Victoria Foe undertook a careful and detailed survey of the cells undergoing cell division in the 14th cycle (Fig. 1A) and published her findings in an impressive paper in Development (Foe 1989). That same year Bruce Edgar and Pat O'Farrell were trying to understand a gene that they had just cloned called string. string mutant embryos arrested in $G_{2}$ after the 13 th cell division, implying that the gene product was required for the cells to go into mitotic division (Edgar and O'Farrell 1989). When they looked at the expression pattern of string RNA in a wild-type cycle 14 embryo, they realized that string was being expressed in exactly the same pattern, with the same temporal appearance, as the mitotic domains that Foe had defined (Fig. 1B). Foe's information represented power for Edgar and $\mathrm{O}^{\prime}$ Farrell, who could now answer the question, "What controls these mitotic domains?" It turned out to be the concentration of string protein.

An early example of DNA sequence information as power comes from work Jeffrey Ravetch did as a postdoc in Philip Leder's lab (Ravetch et al. 1980). While analyzing heteroduplexes between the $\mu$ constant-region immunoglobulin
A

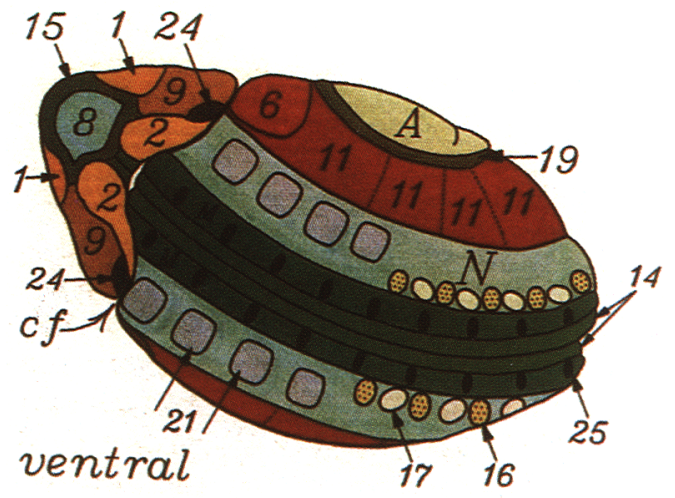

B

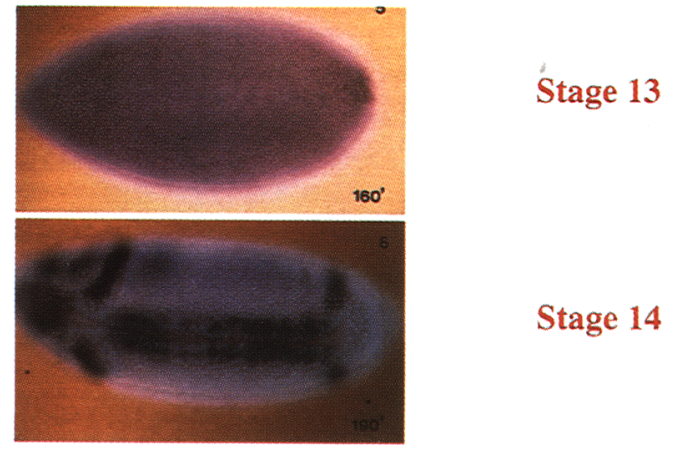

Figure 1 Connecting string to mitotic domains in Drosophila. (A) A map of the mitotic domains of a cycle 14 Drosophila embryo, as determined by Foe (1989). The domains are numbered according to the order in which mitosis occurs during cycle 14. (B) The expression of string RNA in a wild-type embryo during cycle 14 (Edgar et al. 1994). Mitotic domain 1-10 are expressing the RNA, as determined by the staining of RNA with digoxigeninlabeled string cDNA. (Reprinted, with permission, from Edgar et al. 1994. Copyright 1994 Company of Biologists, Ltd.) 


\section{A BIOLOGIST'S VIEW OF THE GENOME PROJECT}

genes of mouse and human using the electron microscope, he noticed that in addition to homoduplexes that represented the four exons that encoded that constant region, there were surprising and unexplained homoduplexes that extended into the intron that separated the variable and constant regions of the genes (Fig. 2). Significant interspecies homology of this kind is like waving a red flag in front of a biologist: "There is something important here; pay attention." Indeed, three years later, Walter Schaffner's and Susumu Tonegawa's labs showed that at least part of this mysterious homology was due to a regulatory sequence-the enhancer that regulates the expression of the $\mu$ constant region gene (Banerji et al. 1983; Gillies et al. 1983). Once again, information, even if you don't understand it at the moment, can be power to another scientist.

The genome sequences that are being generated in the Human Genome Project are beginning to be used in similar ways by biologists. To cite but one example, Mark Rose, a yeast cell biologist at Princeton, has been puzzling for four or five years over the question: Where is the other
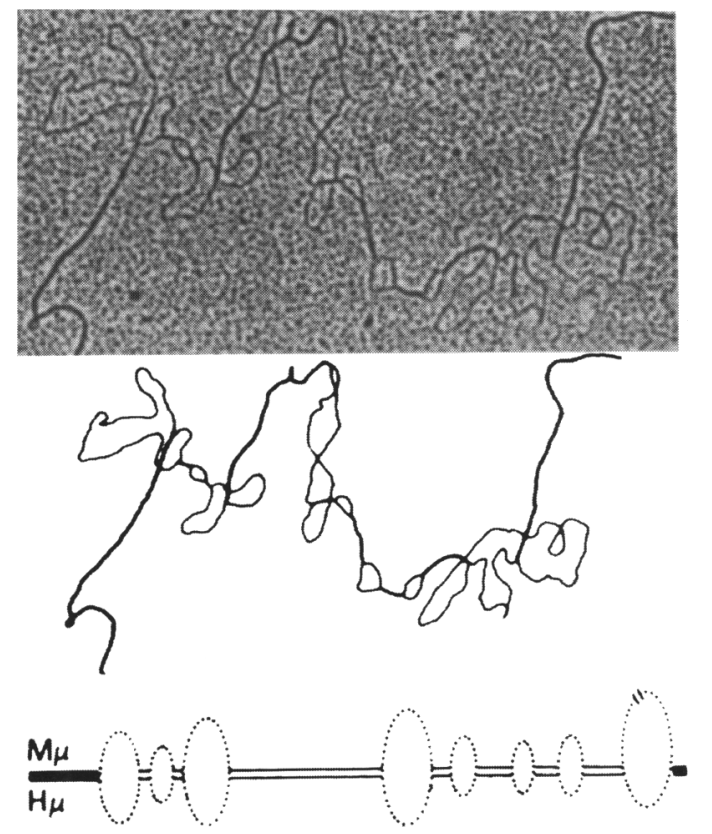

Figure 2 Extensive conservation between mouse and human immunoglobulin heavy chain genes. Heteroduplexes between bacteriophage $\lambda$ clones encoding the mouse and human heavy chain immunoglobulin genes were visualized in the electron microscope. The double-stranded regions represent the four conserved exons of the heavy chain genes, as well as conserved intronic DNA. (Reprinted, with permission, from Ravetch et al. 1980.) kinesin? Kinesin is a microtubule-based motor that is required to move chromosomes apart during cell division. Rose had identified a kinesin called kar3, and had shown that kar3 is required both for chromosome segregation during meiosis and for mating (Meluh and Rose 1990). Mysteriously, however, defects in kar3, or even a complete deletion of the kar3 gene, had a very modest effect on mitosis. So the question was: What is motoring those chromosomes around in mitosis? Where is the other kinesin? Rose can now do a "conceptual" experiment: He can take the yeast genome sequence and look for that other kinesin that he has not been able to find by classical genetic screens. This is information as power to a cell biologist.

\section{Lessons Learned from the Human Genome Project. Lesson 2: The Power of Collective Action}

The next lesson learned is one that I think was a hard one for the biological community: the power of collective action. Biology has been a "cottage industry science," a science that prided itself on the belief that the most creative, imaginative science was going to come out of very small groups of people, consisting of an independent investigator and a number of students and postdoctoral fellows. There is no question that that model works enormously well. It has even accommodated extraordinary efforts by small individual groups that benefited all of biology, in the way the Human Genome Project is doing today. This year's Nobel Prize in Medicine was awarded to Christiane Nüsslein-Volhard and Eric Wieschaus for a genetic screen they did in 1980 that essentially revealed the blueprint of the zygotic genes required for Drosophila development (Nüsslein-Volhard and Wieschaus 1980). The information in that genetic screen created a whole field of Drosophila developmental genetics. The Caenorhabditis elegans cell lineage, worked out by John Sulston and his colleagues at the Medical Research Council (MRC) labs in Cambridge, England, is another example of a truly heroic effort to generate a large framework, an infrastructure that allowed new kinds of biology to be done (Sulston and Horvitz 1977; Sulston et al. 1980).

The Genome Project is this kind of project, but on a much larger scale, and because of the scale, it required collective action. We haven't previously had good examples of this laboratory management strategy in biology-although 


\section{IILGHMAN}

clearly other sciences such as physics have adopted it effectively. It required a change in culture, one that is still evolving as the project proceeds. We had to learn how to apportion credit fairly among a large group of scientists and to integrate scientists from disparate disciplines, such as engineering, computer science, and molecular biology, into an effective team.

This approach required that our funding agencies develop mechanisms to fund and to evaluate these large teams of scientists, scientists who for the first time were being held to production goals. Biology, in turn, has gradually learned to understand and respect the creativity that goes into organizing and conducting these large-scale projects. The new appreciation for collective action is evident in the collaboration between the Jackson Laboratory, the University of Edinburgh, and the MRC unit at Edinburgh to generate a gene expression information resource for the mouse (Ringwald et al. 1994). This data base will give a developmental biologist access to a threedimensional picture of where genes are expressed during specific stages of development. This kind of data base, requiring the integration of work from many laboratories, cannot be created by a single individual, only by collective efforts.

\section{Lessons Learned from the Human Genome Project. Lesson 3: The Power of High-Volume Sequencing}

The Human Genome Project has given us, for the first time, the possibility of high-volume DNA sequencing. By that I mean the possibility of sequencing the same region over and over and over again, as well as sequencing very large amounts of DNA once. One of the fields that is going to be profoundly affected by high-volume sequencing is evolutionary biology. We have already begun to see the fruits of this approach in the studies that are being done by molecular evolutionary biologists. One example is a study of the Drosophila chorion genes by J.C. Martinez-Cruzado from Richard Lewontin's lab, in collaboration with Fotis Kafatos at Harvard. Martinez-Cruzado cataloged all of the changes of amino acids in the chorion genes of a large group of Drosophila species that live on the Hawaiian islands, and revealed a paradox. The paradox is that although the chorion genes, which encode the proteins of the egg shell, are thought to be very rapidly evolving, Martinez-Cruzado's data showed that the actual changes are highly constrained (Fig. 3). For example, in one chorion gene that he se-

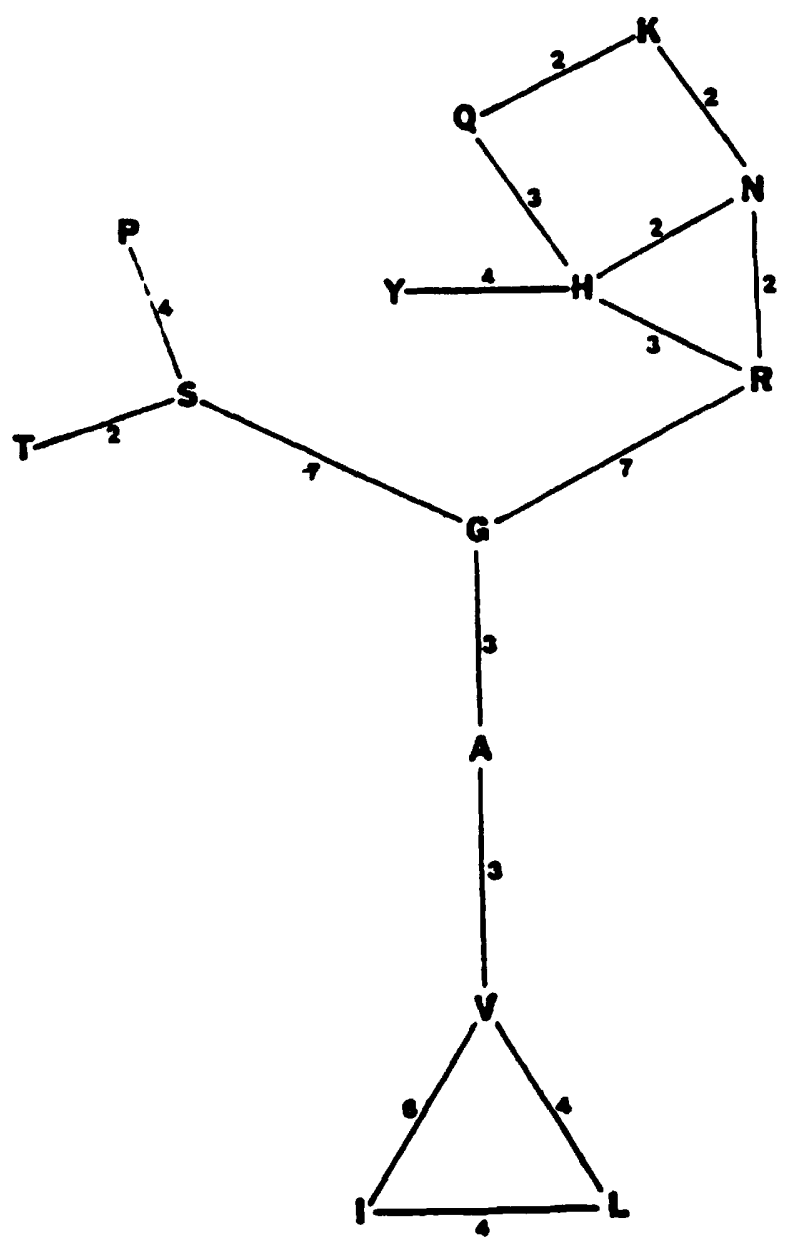

Figure 3 Common amino acid replacements in closely related chorion proteins 518,515 , and 519 found between five taxa of Hawaiian Drosophila as deduced from nucleotide sequences. Only those types of replacements that occurred twice or more are shown. All nucleotide differences found were assumed to be the result of one mutational event. Amino acids at both ends of each line represent the ends of each replacement. Numbers indicate the occurrence of each replacement. (A) Alanine; (G) glycine; (H) histidine; (I) isoleucine; (K) lysine; (L) leucine; $(\mathrm{N})$ asparagine; $(\mathrm{P})$ proline; $(\mathrm{Q})$ glutamine; $(R)$ arginine; $(S)$ serine; $(T)$ threonine; $(V)$ valine; $(Y)$ tyrosine. (Reprinted, with permission, from Martinez-Cruzado 1989.)

quenced from many individuals, both between and among species, alanine changes only to glycine or valine; it never changes to anything else. Evolution had imposed impressive constraints even on these apparently rapidly changing proteins (Martinez-Cruzado 1989).

This kind of sequence information will create an interesting intersection between evolutionary and structural biology. Structural biologists crystallize proteins and model what happens when 


\section{A BIOLOGIST'S VIEW OF THE GENOME PROJECT}

amino acid changes are made at specific positions. They might show that an alanine-tothreonine change in a protein has no effect on either the crystal structure or even on the function of the protein when it is transfected into cells. Nevertheless, the evolutionary biologists will be able to tell the structural biologists, "That may be true in your crystal structure, and it may even be true in your transfected cell, but in nature that alanine is never threonine." Fitness is being selected for in nature in ways that we haven't yet been able to detect in our experimental systems.

\section{Promised Kept by the Human Genome Project. Promise 1: The Power of Making Connections}

Those, I think, are the lessons learned. What are the promises kept? The most important one is the power that the Human Genome Project has given biology to make connections. Here's an example from my own lab where making connections was the key to the project at every step of the way. We had been interested in mouse mutation called Fused. Mice that are heterozygous for the Fused mutation have kinky tails because the somites of the tail fail to develop properly (Fig. 4A). Mice homozygous for the most severe allele of the mutation die as embryos, shortly after the onset of gastrulation, essentially because the embryo tries to develop more than one body axis (Fig. 4B). The Fused mutation was originally described by Reed (1937) and it had sat on the shelves of various mouse colonies for 50 years. It was a fascinating problem that was intractable because there were no tools to get at the nature of the gene. The first tool that the Human Genome Project project brought to bear on this mystery was the improvement in the mouse genetic map, largely through the efforts of Bill Dietrich and Eric Lander at the Massachusetts Institute of Technology (Dietrich et al. 1992, 1996). This allowed a postdoctoral fellow named Jan Rossi to map Fused with high precision using molecular markers (Rossi et al. 1994). It also allowed Frank Costantini to make a connection between Fused and a transgene insertion that had been generated in his laboratory and exhibited an embryonic lethal phenotype. Complementation testing between his transgene and Fused confirmed that the transgene insertion was in Fused (Perry et al. 1995). A high-resolution genetic map allowed a new connection to be made.

The next advance in the project that was a product of the Human Genome Project was made by David Burke, who made the first mouse yeast artificial chromosome (YAC) library in our lab (Rossi et al. 1992). This allowed us to clone the DNA surrounding Fused, which is a large gene, with relative ease. The final connection happened when the transcript was sequenced and compared with all sequences in GenBank. Suddenly, not only did we have hits, we had hits in genes for which functional information was available. The hits were in genes whose products suppress $G$ protein-coupled signaling. Now we had a hypothesis for the function of the Fused

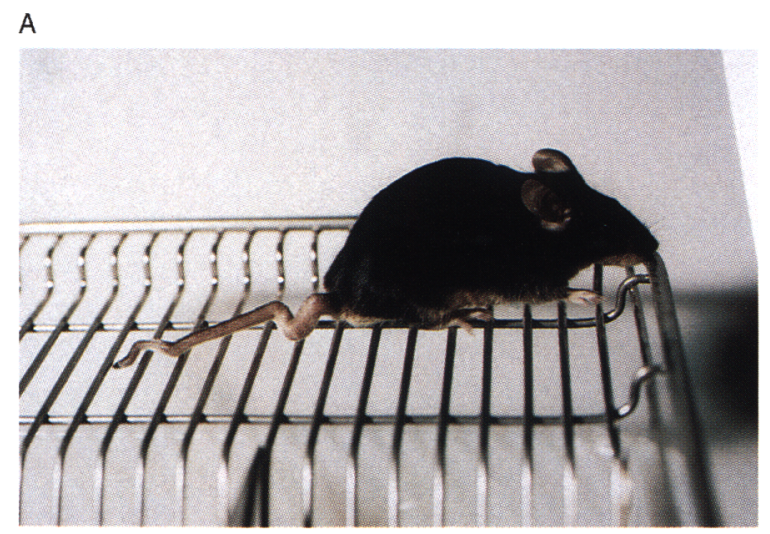

B

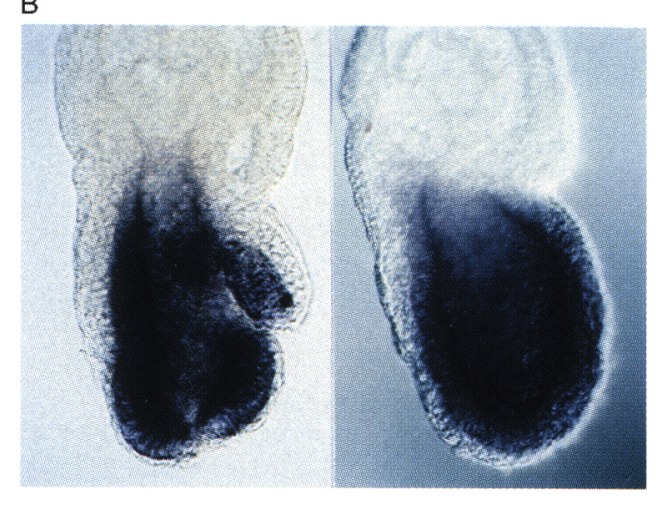

Figure 4 The pheonotypes associated with the Fused ${ }^{\text {Kinky }}$ mutation. (A) A heterozygous Fused $d^{\text {Kinky }} /+$ mouse, exhibiting the dominant kinked tail phenotype. (B) On the right is depicted a Fused ${ }^{k i n k y}$ homozygote at egg cylinder stage. Note the presence of two primitive streaks, one on each side of the embryo. The embryo on the left is a wild-type embryo with one primitive streak on the left side. The embryos are stained by in situ hybridization using a digoxigenin-labeled CDNA probe for Oct-3, a marker of embryonic ectoderm (provided by $\mathrm{T}$. Vasicek and the author). 


\section{IILGHMAN}

gene product: Once the position of the first axis is determined, Fused is involved in suppressing additional axis formation at all other positions in the circumference of the egg cylinder. When the product is missing, multiple axes form. Without this connection that we were able to make because these genes were appearing at such a rapid rate in the data bases, we would still be scratching our heads, trying to figure out what this protein had to do with axis formation. Now, at least, we have a reasonable hypothesis to test.

Connections between genes are being made at a faster pace because of the amount of genetic and sequence information available. In the late 1980 s and early 1990s studies on three very different biological problems were leading to the identification of the same genes (Winston and Carlson 1992; Carlson and Laurent 1994). Groups working on the regulation of the HO endonuclease, required for mating type switching, had identified a series of genes-the SWI genesthat were required for $\mathrm{HO}$ transcription, and had also found suppressors of mutations in those genes. At the same time, Marion Carlson's lab was identifying regulators of invertase synthesis, which is involved in the sucrose metabolism pathway. She had found a series of regulatory genes called $S N F$ genes and had identified suppressors of mutations in some of these genes. Finally, a third group was working on transcription of Ty transposable elements, the TYE genes.

All three groups were, in fact, working on the same set of genes. Their failure to recognize this at the outset was due to the fact that some of the genes had not been cloned and sequenced, but, more important, they hadn't been well mapped. Had they been well mapped, someone might have suspected that $S N F 2$ is the same as $S W I 2$ and that SNF5 is the same as SWI1O and TYE4 (Table 1). Once cloned and sequenced, it became clear why the same genes were acting in such disparate

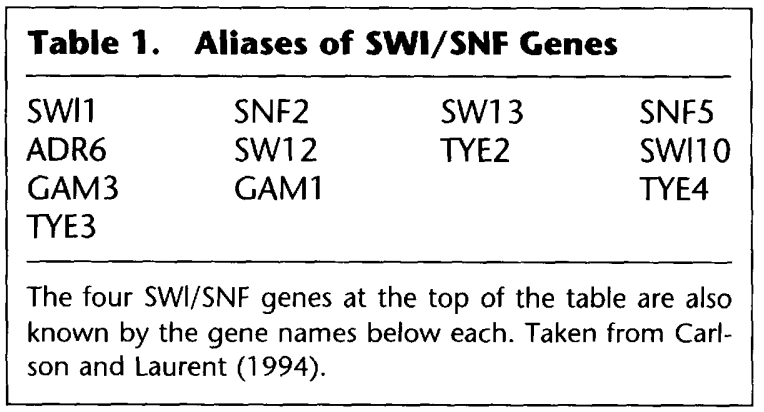

biological processes: The gene products are general regulators of transcription-that is, proteins that affect chromatin structure.

\section{Promises Kept by the Human Genome Project. Promise 2: The Power of Developing Model Organisms}

One of the challenges that faced the designers of the Human Genome Project was to identify the model organisms that would be included. Those chosen constituted what geneticist Gerry Fink calls "the Security Council of organisms"-that is, the ordained, the anointed-those with tractable genetics. By choosing, one ran the risk of the rest of biology getting lost in the shuffle. That hasn't happened, and, if anything, the Human Genome Project has facilitated the birth of new model organisms. For example, the zebra fish certainly wasn't on the original Security Council of model organisms. Nevertheless, the April issue of Genetics contains the report of a high-resolution genetic map of zebra fish put together by John Postlethwait and his colleagues (Johnson et al. 1996). Remarkably, the first paragraph of that paper states that two years ago no two markers in the zebra fish genome were linked to each other. Just two years to get a genetic map that's going to be extraordinarily useful to this community. The mapping technology that was developed for human genetic mapping is now being used to increase the number of organisms for which genetics and genomics will be powerful tools.

Some organisms will never be model organisms, but by studying them we can answer novel questions that are unique to that organism as well as further illuminate principles learned from the study of more traditional organisms. For example, biologist Sean Carroll (Carroll et al. 1994) has been investigating the molecular explanation underlying the beautiful patterns of spots on butterfly wings: What are the genes that direct these spots to their stereotypic positions within a species (Fig. 5)? He's beginning to get the answers from Drosophila, in part because he can move so quickly from a Drosophila gene to a butterfly gene. One tentative answer to the position of the wing spots lies in a gene called distalless, which in the fly is used to define the proximal-distal axis of the wing. In the butterfly distalless is expressed in exactly the positions in the imaginal disk that correspond to the position where the wing spot will later appear. 


\section{A BIOLOGIST'S VIEW OF THE GENOME PROJECT}

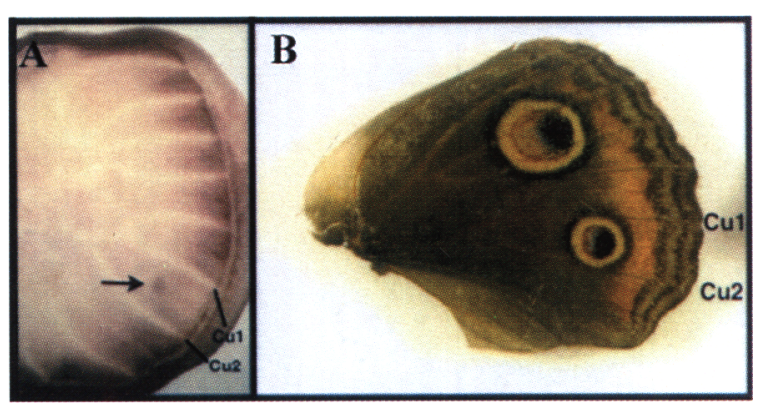

Figure 5 The coincidence of distalless expression with the future wing eyespot. (A) Position of distalless expression in the hindwing imaginal disc, at the same position as the future eyespot. (B) The eyespots on the adult hindwing of the butterfly Precis coenia. (Reprinted, with permission, from Carroll et al. 1994. Copyright 1994 American Association for the Advancement of Science.)

\section{Promises Kept by the Human Genome Project. Promise 3: The Freedom to Do Biology}

The true promise kept by the Human Genome Project is the freedom to do biology. Following upon its discovery in the 1970s, recombinant DNA created a monster, and the monster was cloning and sequencing. For years, you couldn't open an endocrinology journal, a pharmacology journal, a physiology journal, a neurobiology journal without reading papers on cloning and sequencing. The endocrinologists weren't doing endocrinology; they were cloning and sequencing. We should celebrate the fact that we are now beginning to get through the cloning-andsequencing phase and return to what we all wanted to do in the first place, which is to understand the principles and diversity in biology.

One can already see paradigm shifts in the way we think about biology. First, we are moving from gene-centric biology to genome-centric biology. We're thinking about ways of asking questions about a whole genome rather than about a single gene. Geneticists have always done this when they conduct genetic screens, but usually they rapidly homed in on a single gene. I think we will continue to benefit from this approach for a long time to come, but fresh and important new approaches which take a genome-wide view will become more prevalent.

It is exhilarating to think about the transition from studying genome structure to understanding genome function. This is the strongest argument for doing genomic sequencing, as opposed to being content with the EST sequences. The information to understand how chromosomes work is in the genome sequenceand we have to get it. We are already making the transition from using DNA sequencing as a method to verify the cloning of a gene to sequencing as a screen for a gene. I think it's increasingly going to be the way we do gene discovery. Those gene discovery methods will, in some instances, be conceptual, informational, "intellectual" screens. We're going to be asking sequence data bases questions like, "Give me all of the genes in the yeast genome that are regulated by a specific transcription factor. What do they have in common? What are the ways that they interact with each other to create a specific phenotype in yeast?"

So, as you have probably already figured out, I'm a big enthusiast for this wonderful adventure that you're all engaged in. I think you will find that other biologists are watching with intense interest and applauding you with enthusiasm.

\section{REFERENCES}

Banerji, J., L. Olson, and W. Schaffner. 1983. A lymphocyte-specific cellular enhancer is located downstream of the joining region in immunoglobulin heavy chain genes. Cell 33: 729-740.

Carlson, M. and B.C. Laurent. 1994. The SNF/SWI family of global transcriptional activators. Curr. Opin. Cell Biol. 6: 396-402.

Carroll, S.B., J. Gates, D.N. Keys, S.W. Paddock, G.E.F. Panganiban, J.E. Selegue, and J.A. Williams. 1994. Pattern formation and eyespot determination in butterfly wings. Science 265: 109-114.

Dietrich, W., H. Katz, S.E. Lincoln, H.S. Shin, J. Friedman, N.C. Dracopoli, and E.S. Lander. 1992. A genetic map of the mouse suitable for typing intraspecific crosses. Genetics 131: 423-447.

Dietrich, W.F., J. Miller, R. Steen, M.A. Merchant, D. Damron-Boles, Z. Husain, R. Dredge, M.J. Daly, K.A. Ingalls, T.J. O'Connor, C.A. Evans, M.M. DeAngelis, D.M. Levinson, L. Kruglyak, N. Goodman, N.G. Copeland, N.A. Jenkins, T.L. Hawkins, L. Stein, D.C. Page, and E.S. Lander. 1996. A comprehensive genetic map of the mouse genome. Nature 380: 149-152.

Edgar, B.A. and P.H. O'Farrell. 1989. Genetic control of cell division patterns in the Drosophila embryo. Cell 57: $177-187$.

Edgar, B.A., D.A. Lehman, and P.H. O'Farrell. 1994. Transcriptional regulation of string (cdc25): A link 


\section{TILGHMAN}

between developmental programming and the cell cycle. Development 120: 3131-3143.

Foe, V.E. 1989. Mitotic domains reveal early commitment of cells in Drosophila embryos. Development 107: 1-22.

Gillies, S.D., S.L. Morrison, V.T. Oi, and S. Tonegawa. 1983. A tissue-specific transcription enhancer element is located in the major intron of a rearranged immunoglobulin heavy chain gene. Cell 33: 717-728.

Johnson, S.L., M.A. Gates, M. Johnson, W.S. Talbot, S. Horne, K. Baik, S. Rude, J.R. Wong, and J.H.

Postlethwait. 1996. Centromere-linkage analysis and consolidation of the zebrafish genetic map. Genetics 142: $1277-1288$.

Martinez-Cruzado, J.C. 1989. "Evolution of the organization and DNA sequence of the autosomal chorion gene cluster in Hawaiian Drosophila." Ph.D. dissertation, Harvard University, Cambridge, MA.

McIntosh, J.R. and R.R. West. 1995. A cell biological perspective on genome research. J. Cell Biol.

131: $1361-1364$.

Meluh, P.B. and M.D. Rose. 1990. KAR3, a

kinesin-related gene required for yeast nuclear fusion.

Cell 60: 1029-1041.

Nusslein-Volhard, C. and E. Wieschaus. 1980. Mutations affecting segment number and polarity in Drosophila. Nature 287: 795-801.

Perry, W.L., III, T.J. Vasicek, J.J. Lee, J.M. Rossi, L. Zeng, T. Zhang, S.M. Tilghman, and F. Costantini. 1995. Phenotypic and molecular analysis of a transgenic insertional allele of the mouse Fused locus. Genetics 141: $321-332$.

Ravetch, J.V., I.R. Kirsch, and P. Leder. 1980. Evolutionary approach to the question of immunoglobulin heavy chain switching: Evidence from cloned human and mouse genes. Proc. Natl. Acad. Sci. 77: 6734-6738.

Reed, S.C. 1937. The inheritance and expression of Fused, a new mutation in the house mouse. Genetics 22: $1-13$.

Ringwald, M., R. Baldock, J. Bard, M. Kaufman, J. Eppig, J. Richardson, J. Nadeau, and D. Davidson. 1994. A database for mouse development. Science 265: 2033-2034.

Rossi, J.M., D.T. Burke, J.C. Leung, D.S. Koos, H. Chen, and S.M. Tilghman. 1992. Genomic analysis using a yeast artificial chromosome library with mouse DNA inserts. Proc. Natl. Acad. Sci. 89: 2456-2460.

Rossi, J.M., H. Chen, and S.M. Tilghman. 1994. Genetic map of the Fused locus on mouse chromosome 17. Genomics 23: 178-184.
Sulston, J.E. and H.R. Horvitz. 1977. Post-embryonic cell lineages of the nematode, Caenorhabditis elegans. Dev. Biol. 56: 110-156.

Sulston, J.E., D.G. Albertson, and J.N. Thomson. 1980. The Caenorhabditis elegans male: Postembryonic development of nongonadal structures. Dev. Biol. 78: $542-576$.

Winston, F. and M. Carlson. 1992. Yeast SNF/SWI transcriptional activators and the SPT/SIN chromatin connection. Trends Genet. 8: 387-391. 


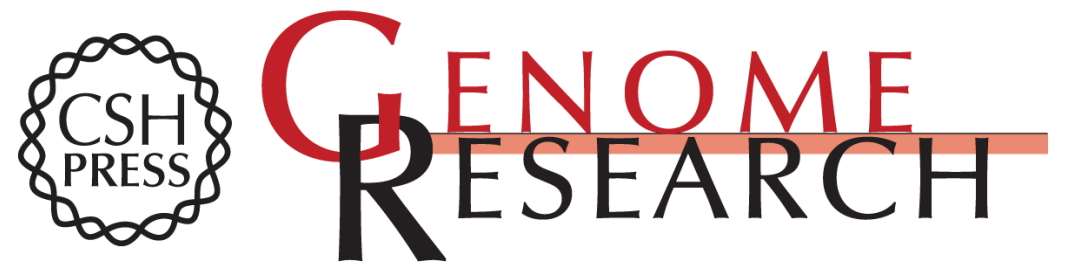

\section{Lessons learned, promises kept: a biologist's eye view of the Genome Project.}

S M Tilghman

Genome Res. 1996 6: 773-780

Access the most recent version at doi:10.1101/gr.6.9.773

References This article cites 22 articles, 11 of which can be accessed free at:

http://genome.cshlp.org/content/6/9/773.full.html\#ref-list-1

\section{License}

Email Alerting Receive free email alerts when new articles cite this article - sign up in the box at the Service top right corner of the article or click here.

\section{Affordable, Accurate Sequencing.}

To subscribe to Genome Research go to: https://genome.cshlp.org/subscriptions 